\title{
Moderasi Beragama dan Radikalisme di Era Modern
}

\author{
Ibnu Hajar Sainuddin \\ Sekolah Tinggi Agama Islam Darud Da'wah Wal-Irsyad Makassar \\ Email: ibnuhajar@staiddimakassar.ac.id
}

\begin{abstract}
Abstrak
Di era modern, kemajuan teknologi merupakan suatu keharusan. Dengan kemajuan teknologi, maka muncul pula pemikiran-pemikiran yang modern. Ini dilatar belakangi berbagai aspek seperti aspek agama, pendidikan, ekonomi, sosial, politik dan budaya. Seiring perkembangan pemikiran juga muncul paham-paham yang radikal. Moderasi beragama merupakan sebagai jalan tengan dalam mencegah terjadinya paham radikal di masyarakat. sikap salin menghormati antar pemeluk agama juga merupakan suatu keharusan yang harus dijalankan sebagai sikap pluralisme.
\end{abstract}

Kata kunci: Moderasi beragama, radikalisme, era modern.

\section{Pendahuluan}

Islam merupakan agama dakwah yang disebarluaskan mulai dari Nabi sampai kepada umat yang sekarang (Alam, L. 2016). Dengan penyebaran agama Islam yang semakin luas, maka semakin luas pula pemahaman tentang Islam. Seiring berjalannya waktu, umat Islam untuk saling menghargai satu sama lain, baik kepada pemeluk agama yang sama maupun pemeluk agama yang berbeda.

Di era modern, perkembangan ilmu ilmu pengetahuan dan teknologi juga membuat berbagai macam aliran pemahaman muncul (Rofiq, M. N. 2018). Baik pemahaman yang moderat bahkan sampai aliran pemahaman yang radikal. Islam menjadi salah satu yang berperan penting dalam menjaga keutuhan baik beragama maupun bermasyarakat.

Munculnya paham radikalisme dalam masyarakat menjadi tugas bersama dalam memfilter informasi-informasi yang diterima (Sabiruddin, S. 2019). Moderasi beragama menjadi jalan penengah bagi tercitanya kedamaian di tengah umat. Timbulnya paham dan gerakan radikal akibat dari pemahaman agama yang masih kurang (Sainuddin, I. H., S, Arsyam, M., \& Alwi, A. M. S. (2020, August 19).. Radikalisme menjadi tantangan bagi umat Islam dan masyarakat secara umum. Oleh karena itu, maka moderasi beragama sangat penting dalam kehidupan bermasyarakat terlebih di era modern yang dimana serba teknologi.

\section{Pembahasan}


Di era modern dan serba teknologi, muncul pula pemikiran-pemikiran yang modern. Tentunya pemikiran-pemikiran tersebut tidak terlepas dari bermacam aspek seperti aspek pendidikan, sosial, ekonomi, politik bahkan keagamaan. Modernisasi dalam bidang sains dan teknologi, manusia dituntut untuk terus maju dan mampu beradaptasi pada segala lini kehidupan (Mahfudz, A. 2016).. Pada era kemajuan ini ini membawa dampak kemajuan pada masyarakat. Sosial media menjadi salah satu dampak dari kemajuan teknologi (Sainuddin, I. H., S. 2020, July 27). Di sisi lain dengan kemajuan teknologi, agama tidak bisa terlepas dan merupakan menjadi pedoman bagi manusia dalam menentukan arah hidup ke depan (Amran, A. 2015). Salah satu itu yang menjadi dampak dari era modernisasi adalah fenomena radikalisme.

Fenomena radikalisme yang muncul dan terjadi dimulai di wilayah timur tengah (Asrori, A. 2015). Ini terjadi akibat dari terjadinya krisis identitas yang dimana merupakan mayoritas beragama menolak terjadinya modernisasi. Dengan penolakan terhadap modernisasi yang dicanangkan oleh negara barat kepada masyarakat Islam, maka terjadi sebuah kemunduran. Kemudian akibat dari penolakan tersebut, maka muncul paham radikal dalam tatanan masyarakat Islam sehingga terjadi kemerosotan moral dan agama yang disebabkan oleh kemajuan teknologi sehingga ilmu pengetahuan dalam modernisasi pemahaman Islam yang berhaluan Barat (Makhmudah, S. 2015).

Munculnya paham radikalisme merupakan suatu bentuk dari ekspresi orang Islam yang dilakukan secara berlebihan dalam merespon permasalahan sosial agama dan politik yang yang berlebihan sehingga mengakibatkan muncul sikap yang di luar batas kewajaran manusia (Faiqah, N., \& Pransiska, T. 2018). Salah satu Yang menjadi fenomena gerakan kelompok radikal umat beragama dan mengatasnamakan Islam yaitu kelompok Islamic State of Iraq and Syria (ISIS) (Santuso, A. G., Rifaini, E., \& Adi, D. P. 2020). Islamic State of Iraq and Syria (ISIS) merupakan kelompok gerakan radikal yang ingin membentuk suatu negara yang berdasarkan syariat Islam. Dengan adanya gerakan kelompok radikal seperti Islamic State of Iraq and Syria tersebut memiliki tujuan mendirikan negara yang berasaskan syariat Islam akan tetapi cara yang dilakukan tidak sesuai dengan syariat Islam (Haryadi, A., \& Muthia, N. 2017). Bahkan kelompok tersebut melakukan perluasan kekuasaan sampai ke seluruh dunia dengan membawa atas hukum Islam dengan mengatas namakan jihad. Akan tetapi jika diperhatikan secara seksama bahwa sebenarnya organisasi ini lebih mengarah pada paham paham radikalisme, yang di mana tidak sesuai dengan hukum Islam yang berlaku. Paham radikalisme yang dibawa oleh Islamic State of Iraq and Syria 
merupakan lebih mengarah kepada ada sikap fanatisme yang dilakukan secara berlebih-lebihan (Afandi, M. H. 2016)..

Istilah radikal atau radikalisme muncul dan dicetuskan oleh negara-negara Barat. Di mana pemahaman tersebut dianggap sebagai paham yang keras dan mengandung kekerasan dengan mengatasnamakan agama terutama agama Islam (Halimah, S. 2018).. Oleh karena itu maka paham radikal merupakan suatu pemahaman yang menyimpang terhadap agama serta sikap yang berlebihlebihan sehingga jalan kebenaran melewati batas yang telah ditentukan oleh agama.

Di era modern agama memiliki peran penting dalam masyarakat sebagai pedoman serta memposisikan diri untuk berdampingan dengan zaman yang yang terus maju dan berkembang sehingga tidak menyimpang. Di sisi lain, perkembangan demokrasi serta kemajuan teknologi informasi tentunya masyarakat dari berbagai lapisan dengan mudah mengetahui hal-hal yang berkaitan dengan agama (Rahmawanto, S. 2016). Informasi keagamaan dapat dengan mudah dikemas baik dalam bentuk buku video atau di berbagai platform media sosial. Disisi lain, Moderasi beragama juga mampu mempengaruhi kesehatan mental (Munir, M. B., \& Herianto, H. 2020). Dengan demikian, bahwa sesungguhnya Islam telah siap menghadapi dan mengambil peran bagi umat Islam di era modern Apakah sebagai penonton atau sebagai pemeran aktif dan pemotor kekuatan dalam kemajuan Islam.

Di sisi lain fenomena kekerasan dan intoleransi antara umat beragama masih terus terjadi di berbagai tempat di Indonesia. Banyaknya kekerasan yang dialami antar umat beragama dilatarbelakangi karena ketidak kesesuaian komunikasi antara dua belah pihak (BIDAYA, Z., \& UMAMI, R. 2016). Disaat intoleransi kian marak serta kekerasan atas nama agama serta moral atau moralitas yang berlangsung terjadi di di Indonesia.

Indonesia merupakan bangsa yang memiliki keanekaragaman budaya, ras, etnis, bahasa dan agama (Mubit, R. 2016). Namun hal tersebut bukan menjadi kendala untuk berbeda antara satu dengan yang lain. bahwa perbedaan tersebut merupakan suatu kelebihan yang dimiliki untuk mempererat dalam bingkai keragaman.

Pluralisme dalam pandangan Islam merupakan sikap saling menghormati dan toleransi antar pemeluk agama dan suatu kemutlakan yang harus dijalankan (Mantik, A. 2017). Akan tetapi pluralisme bukan berarti menganggap bahwa semua agama sama. Dalam Islam pluralisme agama diakui dengan adanya perbedaan an dan masing-masing agama mempunyai identitas (Saihu, S. 
2019). Pluralisme agama berorientasi dan untuk menghilang konflik serta menghilangkan sekat perbedaan serta identitas-identitas keagamaan.

Di Indonesia beberapa tahun belakangan ini sering terjadi konflik horizontal merujuk pada SARA (Nugraha, A. Y. 2019).. Seperti peristiwa penyerangan kelenteng, gereja di bom, masjid dibakar bahkan ormas-ormas melakukan tindak kekerasan. Isu agama bisa menjadi komoditi yang paling mudah untuk dijadikan sebagai pemicu konflik (Wekke, I. S. 2016). Bentrokan terjadi antara masa pendukung suatu kelompok yang berbasis agama banyak terjadi di sana dianggap sebagai biang kerok.

Oleh karena itu, moderasi beragama di era modern sangat penting. Moderasi beragama sebagai jalan tengah dalam menyatukan perbedaan baik sesama agama maupun berbeda agama. Moderasi beragama pula dapat mencegah terjadinya radikalisme dalam masyarakat. Sehingga paham radikal yang terjadi di masyarakat dapat dicegah dan diminimalisir.

\section{Penutup}

Di era modern, paham-paham radikal dapat ternalisir dengan konsep moderasi beragama. Islam menjadi salah contoh dalam implemtasi moderasi beragama. Moderasi beragama menjadi jalan tengah sekaligus sebagai solusi agar tidak terjadi paham yang radikal bahkan intoleran. Saling hormat dan menghormati antar agama menjadi kunci agar tidak terjadi sekat dan perbedaan sekaligus sebagai identitas yang harus dimiliki antar umat beragama. 


\section{DAFTAR PUSTAKA}

Afandi, M. H. (2016). Menghadang Radikalisme di Bumi Nusantara. Jurnal Lentera: Kajian Keagamaan, Keilmuan dan Teknologi, 14(1), 73-87.

Alam, L. (2016). Internalisasi nilai-nilai pendidikan islam dalam perguruan tinggi umum melalui lembaga dakwah kampus. Istawa: Jurnal Pendidikan Islam, 1(2), 101-119.

Amran, A. (2015). Peranan agama dalam perubahan sosial masyarakat. HIKMAH: Jurnal Ilmu Dakwah dan Komunikasi Islam, 2(1), 23-39.

Asrori, A. (2015). Radikalisme di Indonesia: Antara Historisitas dan Antropisitas. Kalam, 9(2), 253-268.

BIDAYA, Z., \& UMAMI, R. (2016). IMPLEMENTASI UNDANG-UNDANG NO. 23 TAHUN 2004 TENTANG PENGHAPUSAN KEKERASAN DALAM RUMAH TANGGA (PKDRT) BERKAITAN DENGAN PRANATA LOKAL DI DESA SOKONG KECAMATAN TANJUNG KABUPATEN LOMBOK UTARA. CIVICUS: PendidikanPenelitian-Pengabdian Pendidikan Pancasila dan Kewarganegaraan, 4(2), 30-39.

Faiqah, N., \& Pransiska, T. (2018). Radikalisme Islam Vs Moderasi Islam: Upaya Membangun Wajah Islam Indonesia Yang Damai. Al-Fikra: Jurnal Ilmiah Keislaman, 17(1), 33-60.

Halimah, S. (2018). Memangkas Paham Intoleran dan Radikalisme melalui Pembelajaran Agama Islam yang Bervisi Rahmatan Lil Alamin. Jurnal Al-Makrifat Vol, 3(2).

Haryadi, A., \& Muthia, N. (2017). Gerakan Politik Negara Islam Irak dan Suriah (ISIS) dan Pengaruhnya terhadap Indonesia. Jurnal Transborder, 1(1).

Makhmudah, S. (2015). Dinamika dan Tantangan Masyarakat Islam di Era Modernisasi. Jurnal Lentera: Kajian Keagamaan, Keilmuan dan Teknologi, 1(2), 242-259.

Mantik, A. (2017). IMPLEMENTASI NILAI-NILAI PLURALISME BERDASARKAN NILAINILAI BUDAYA BANGSA. JPGMI (Jurnal Pendidikan Guru Madrasah Ibtidaiyah AlMultazam), 2(1), 1-15.

Mubit, R. (2016). Peran Agama dalam Multikulturalisme Masyarakat Indonesia. Epistemé: Jurnal Pengembangan Ilmu Keislaman, 11(1), 163-184.

Munir, M. B., \& Herianto, H. (2020). Tingkat Pemahaman Moderasi Beragama Serta Korelasinya Terhadap Pengaruh Kesehatan Mental, Keaktifan Berorganisasi dan Prestasi Akademik. Prosiding Nasional, 3, 137-150. 
Nugraha, A. Y. (2019). Tema Cinta Beda Suku, Adat, Ras, Dan Agama Dalam Film Tanda Tanya (2011) Sebagai Wacana Pemersatu Bangsa. Jurnal Kajian Islam Interdisipliner, 2(2).

Rahmawanto, S. (2016). Peran Tokoh Agama dalam Mewujudkan Keteraturan Masyarakat. AnNidzam: Jurnal Manajemen Pendidikan dan Studi Islam, 3(1), 118-134.

Rofiq, M. N. (2018). Peranan Filsafat Ilmu Bagi Perkembangan Ilmu Pengetahuan. FALASIFA: Jurnal Studi Keislaman, 9(1), 161-175.

Sabiruddin, S. (2019). Saring sebelum Sharing, Menangkal Berita Hoax, Radikalisme di Media Sosial. AL MUNIR: Jurnal Komunikasi dan Penyiaran Islam, 22-40.

Saihu, S. (2019). Pendidikan Pluralisme Agama: Kajian tentang Integrasi Budaya dan Agama dalam Menyelesaikan Konflik Sosial Kontemporer. Jurnal Indo-Islamika, 9(1), 67-90.

Sainuddin, I. H., S, Arsyam, M., \& Alwi, A. M. S. (2020, August 19). Pemahaman Makna Tauhid dan Dua Kalimat Syahadat. https://doi.org/10.31219/osf.io/g84vu Mahfudz, A. (2016). Menghadapi Tantangan Modernisasi Dengan Mewujudkan Kualitas Manusia Indonesia Melalui Peneguhan Pendidikan Moral. Jurnal Ilmu Pendidikan, 2(3).

Sainuddin, I. H., S. (2020, July 27). Dakwah di Era Sosial Media. https://doi.org/10.31219/osf.io/2jxny

Wekke, I. S. (2016). Harmoni Sosial Dalam Keberagaman Dan Keberagamaan Masyarakat Minoritas Muslim Papua Barat. Kalam, 10(2), 295-312. 